\title{
APPLICATION OF SINGULAR INTEGRAL EQUATIONS IN SOLVING SOME CONTACT PROBLEMS IN THEORY OF ELASTICITY
}

\author{
V. Gavdzinski ${ }^{1}$, M. G. El-Sheikh ${ }^{2}$, E. Maltseva ${ }^{3}$ \\ ${ }^{1}$ Odessa State Academy of Civil Engineering and Architecture \\ ${ }^{2}$ Ain Shams University, Cairo, Egypt \\ ${ }^{3}$ Odessa National Economic University
}

\begin{abstract}
In this paper the modification can be used to find an expression of the unbounded contact stress in the theory of elasticity. The vertical vibrations of a punch lying on an elastic isotropic rectangle under harmonic force are considered. This mixed boundary value problem is reduced to a discrete Riemann problem connecting the Fourier components of the required extension of the unknown functions. Separation of the singular part of the discrete problem leads to the Hilbert type singular integral equation, rather than of the Cuchy's kernel one.

The unknown function in this integral equation is normal contact stress. Thus, it is possible to search for the physically interesting unbounded solution. The inversion of the integral equation provided an expression of that solution in terms of its Fourier components. To complete the definition of this expression, that is, to determine these Fourier components presented therein, it is further reduced to an infinite system of algebraic equations through application of the Fourier transforms. The solution of this system completes the definition with the aid of the physical conditions. The solution of this system can be obtained approximately by means of the truncation. The truncation of the algebraic system of equations is justified by using the corresponding theorem. It is supposed that the appropriate homogeneous system has only trivial solution in some space. Then the infinite system has a unique solution. The truncated system has a unique solution and the error is estimated. We assume that the frequency differs from those values for which the homogeneous system corresponding to the given system of equations has nontrivial solutions. On choosing the number of equation and using the formula for determination of the contact stress we can get an approximate solution of the contact problem for rectangle to find a contact stress up to any prescribe accuracy. The resonance frequencies are the real roots of some resonance equations. In the dimensionless frequency, time and coordinate the table of the values of the contact stress corresponding to different values of coordinate is given. The values of the contact stress increase unboundedly at the vicinities of the end points of the contact interval.
\end{abstract}

Keywords: contact, discrete, elasticity, equation, punch, singular.

\section{ЗАСТОСУВАННЯ СИНГУЛЯТОРНИХ ІНТЕГРАЛЬНИХ РІВНЯНЬ ПРИ РІШЕННІ ДЕЯКИХ КОНТАКТНИХ ЗАВДАНЬ ТЕОРЇ̈ ПРУЖНОСТІ}

\author{
Гавдзинський В. Н. ${ }^{1}$, Ель-Шейх М. Г. ${ }^{2}$ Мальцева С. В. \\ ${ }^{1}$ Одеська державна академія будівництва та архітектури \\ ${ }^{2}$ Університет Айн Шамс, Каӥр, Єzипет \\ ${ }^{3}$ Одеський наиіональний економічний університет
}

Анотація. У цій роботі модифікація постановки задачі пов'язаною 3 сингулярним інтегральним рівнянням використовується для знаходження необмеженого контактного напруження в теорії пружності. Розглядаються вертикальні коливання штампу того, що лежить на пружному ізотропному прямокутнику під дією гармонійної сили. Ця змішана гранична 
задача зводиться до дискретної задачі Римана відносно коефіцієнтів Фур’є невідомих функцій. Виділення сингулярної частини дискретної задачі приводить до сингулярного інтегрального рівняння $з$ ядром Гілберта. Звернення цього рівняння дозволяє знайти контактне напруження i звести задачу до нескінченної системи алгебраїчних рівнянь. Усікання системи алгебраїчних рівнянь обгрунтоване i погрішність оцінена. Вибираючи число рівнянь, i використовуючи формулу для визначення контактного напруження для прямокутника, отримуємо наближене рішення контактної задачі з наперед заданої точністю. Резонансні частоти є дійсними коренями відповідних резонансних рівнянь. Приведена таблиця значень контактного напруження того, що відповідає різним значенням безрозмірної координати. Значення контактного напруження збільшуються необмежено в околицях кінцевих точках контактного інтервалу.

Ключові слова: дискретний, контакт, рівняння, сингулярний, пружність, штамп. 


\section{INTRODUCTION}

Contact interaction in deformable bodies plays an important role in assessing the stressstrain state, therefore the solution of contact problems is very important and relevant. Analytical solutions can be obtained only for a limited class of problems in the mechanics of a deformable solid. Extensive possibilities for solving contact problems are presented by modern computer programs, but the obtained results require verification, therefore, further development of applied methods of mathematical modeling with respect to solving contact problems of mechanics and the development of new efficient algorithms are necessary.

\section{ANALYSIS OF LITERARY DATA AND RESOLVING THE PROBLEM}

In 1961 Cherskii Y. I. proposed the method of the discrete Riemann problems for solving some plane mixed boundary value problems [1]. The unknown of this integral equation is an extension of one of the partially imposed conditions and is compatible to the other. It has become of wide applications in several branches of mathematical physics [2]. In 1992 [3] the method of the integral equation was extended to include problems in the theory of elasticity. In the paper [4] the contact elastic problem for an infinite strip with the force prescribed at the stressed segments was given. This problem was reduced to the Hilbert type singular integral equation. The Hilbert equation was inverted to define the contact stress and further reduced to an infinite algebraic system of equations, its solution completes the definition with the aid of the physical conditions. The truncation of the algebraic system was justified and the error was estimated. By Gavdzinski V. N., El-Sheikh M. G. and Maltseva E. V. was given the justification of approximate unbounded solutions of mixed plane boundary value problems and was fully justified and the error was estimated [5]. This was the class to which lot of mixed plane boundary value problems are reducible. An example was given in which the procedures were carried out right to the numerical results.

In the paper [6] the contact problem of symmetric indentation of two punches in the form of circular segments without friction, into the exterior surface of a cylinder under harmonic force $P=P_{0} e^{-i w t}$ and the temperature field was considered. The expression for the contact stress was found and the estimation of the error of the approximate solution was given.

\section{PURPOSE AND TASKS OF THE STADY}

In solving the contact problem for a rectangle under harmonic force $P=P_{0} e^{-i w t}$ our aim is 1) to find an approximate solution of the problem 2) to justify the truncation of the system of algebraic equations 3 ) to estimate the error of the approximate solution 4) to investigate the vertical vibrations of a punch lying on an elastic isotropic rectangle 5) to find resonance frequencies for which the displacement tends to infinity 6) to carry out the procedures right to the numerical results.

\section{METHODS OF RESEARCH}

Using the Fourier transform the problem is reduced to the following discrete Riemann problem

$$
n \Phi_{n+}=-A_{\alpha \beta} \operatorname{sgn}\left(n+\frac{1}{2}\right) \Phi_{n-}+\Gamma_{n}^{\alpha \beta} \Phi_{n-}-n V_{n-},
$$


where $\alpha=w / c_{1}, \beta=w / c_{2}$ and $\Phi_{n-}$ are the Fourier components of the required unbounded extension $\varphi_{-}(x)$ that differs than zero on an internal $\Delta_{1} ; \Phi_{n+}$ are those of $\varphi_{+}(x)$ the extension of the complementary conditions on $\Delta_{2}$. The factor $\Gamma_{n}^{\alpha \beta}$ differ from problem to another but always $\left|\Gamma_{n}^{\alpha \beta}\right|=0\left(1 / n^{2}\right)$. On performing the inverse

Fourier transform

$$
w^{-1} \Phi_{n \pm}=\sum_{n=-\infty}^{\infty} \Phi_{n \pm} e^{i n x}=\varphi_{ \pm}(x)
$$

the discrete Riemann problem is reduced to the Hilbert type singular integral equation

$$
\frac{1}{2 \pi} \int_{-a}^{a} \cot \frac{t-x}{2} \varphi_{-}(t) d t=-2 \sum_{n=1}^{\infty} \Gamma_{n}^{\alpha \beta} \Phi_{n-} \sin n x .
$$

The inversion of this equation defines $\varphi_{-}(x)$ in terms of infinite number of unknowns: its Fourier components and therefore, this equation can in general be only approximately solved. The approximation is achieved by truncating the infinite system of algebraic equations with respect to $\Phi_{n-}$. The justification of the truncation is perform by using the corresponding theorem on the existence of a unique solution in $L_{\rho}(-a, a)$, where $1<\rho<4 / 3$. Consequently the Fourier coefficient $\Phi_{n-}$ will belong to $l_{p}$, where $p=\rho /(\rho-1)$. Thas we will work in the space $l_{p}(p>4)$ with the norm

$$
\Phi_{l_{p}}=\left(\sum_{n=0}^{\infty}\left|\Phi_{n-}\right|^{p}\right)^{1 / p} .
$$

We show that the approximate solution approaches the unique exact solution when the order of truncation increases indefinitely and the error resulting due to the truncation is of the form

$$
\left\|\Phi-\Phi^{N}\right\|_{l_{p}} \leq \frac{C}{(N+1)^{(p-2) / 2 p}} .
$$

\section{BASIC RESULTS}

Now we consider the vertical vibrations of a punch lying on an elastic isotropic rectangle under harmonic force $P=P_{0} e^{-i w t}$.

In view of the statement of the problem the boundary conditions are

$$
\begin{aligned}
& v(x, 0, t)=v_{0} e^{-i w t}, \text { if } x \in \Delta_{1}, \\
& \sigma(x, 0, t)=0, \text { if } x \in \Delta_{2}, \\
& \tau(x, 0, t)=0, \text { if } x \in \Delta_{1} \cup \Delta_{2}, \\
& u(x, h, t)=v(x, h, t)=0, \text { if } x \in \Delta_{1} \cup \Delta_{2}, \\
& u( \pm \pi, y, t)=\tau_{x y}( \pm \pi, y, t)=0, \text { if } x \in \Delta_{3},
\end{aligned}
$$

Where $v_{0}$ is the unknown amplitude of the vibration; 


$$
\Delta_{1}=[-a, a], \Delta_{2}=[-\pi, \pi] / \Delta_{1}, \Delta_{3}=[0, h]
$$

Since $v_{0}$ is a constant, then $v(x, y, t)$ and $\sigma_{y}(x, y, t)$ are the even functions and $u(x, y, t)$ and $\tau_{x y}(x, y, t)$ are the odd functions with respect to $x$.

The substitution for the components of the displacements by the expressions

$$
u=\frac{\partial \Phi}{\partial x}+\frac{\partial \Psi}{\partial y}, v=\frac{\partial \Phi}{\partial x}-\frac{\partial \Psi}{\partial y},
$$

where $\Phi$ and $\Psi$ are the longitudinal and transversal potentials, into the familiar equations

$$
\nabla^{2} \Phi=\frac{1}{c_{1}^{2}} \frac{\partial^{2} \Phi}{\partial t^{2}}, \nabla^{2} \Psi=\frac{1}{c_{2}^{2}} \frac{\partial^{2} \Psi}{\partial t^{2}}, \text { where } c_{1}^{2}=\frac{2 G}{\rho(1-v)}, c_{2}^{2}=\frac{G}{\rho},
$$

and $\rho$ is the density; $G$ is the modulus of elasticity; $v$ is Poisson's ratio.

The potential $\Phi$ and $\Psi$ can be thought of the form

$$
\Phi(x, y, t)=\Phi^{*}(x, y) e^{-i \omega t}, \quad \Psi(x, y, t)=\Psi^{*}(x, y) e^{-i \omega t},
$$

where

$$
\nabla^{2} \Phi^{*}+\alpha^{2} \Phi^{*}=0, \quad \nabla^{2} \Psi^{*}+\beta^{2} \Psi^{*}=0, \quad \alpha=\frac{w}{c_{1}}, \quad \beta=\frac{w}{c_{2}} .
$$

Boundary conditions (1) and (2) can be completed as follows

$$
v^{*}(x, o)=v_{-}(x)+\varphi_{+}(x), \quad \sigma_{y}^{*}(x, o)=\varphi_{+}(x),
$$

where

$$
v(x, y, t)=v^{*}(x, y) e^{-i \omega t}, \quad \sigma_{y}(x, y, t)=\sigma_{y}^{*} e^{-i \omega t},
$$

and $\varphi_{+}(x)=\left\{\begin{array}{ll}0, & x \in \Delta_{1} \\ \text { undetermined, } & x \in \Delta_{2}\end{array} ; \quad \varphi_{-}(x)=\left\{\begin{array}{ll}\text { undetermined }, & x \in \Delta_{1} \\ 0, & x \in \Delta_{2}\end{array} ;\right.\right.$

$$
v_{-}(x)=\left\{\begin{array}{ll}
v_{0,} & x \in \Delta_{1} \\
0, & x \in \Delta_{2}
\end{array} .\right.
$$

Working in the same way as in [4] we arrive at the following discrete Riemann problem

$$
\Phi_{n+}=M_{n}^{h} \Phi_{n-}-V_{n-}(n=0, \pm 1, \pm 2, \ldots)
$$

where

$$
M_{n}^{h}=\frac{S_{n}^{h}}{P_{n}^{h}}, T_{1 n}^{h}=k_{2 n}\left(P_{n}^{w} \cosh \left(k_{2 n} h\right)-2 G_{n}^{2} \cosh \left(k_{1 n} h\right)\right),
$$

Now we estimate coefficients $M_{n}^{h}$ and $\frac{T_{n}^{h}}{P_{n}^{h}}$ as $n \rightarrow \infty$

$$
\begin{aligned}
& M_{n}^{h}=-A_{\alpha \beta} \frac{1}{|n|}+0\left(\frac{1}{n^{2}}\right), \frac{T_{n}^{h}}{P_{n}^{h}}=-\frac{B_{\alpha \beta}}{\cosh \left(k_{2 n} h\right)}+0\left(\frac{1}{\cosh \left(k_{1 n} h\right)}\right), \\
& T_{2 n}^{h}=\operatorname{in}\left(2 G k_{1 n} k_{2 n} \sinh \left(k_{2 n} h\right)\right)
\end{aligned}
$$




$$
\begin{aligned}
& P_{n}^{h}=T_{1 n}^{h}\left(P_{n}^{w} \cosh \left(k_{1 n} h\right)-2 G n^{2} k_{2 n} h\right)\left(\rho u^{2} T_{2 n}^{h}\right)-i n\left(\rho u^{2} k_{1 n}\right)^{-1} \\
& \left(P_{n}^{w} \sinh k_{1 n}-2 G k_{1 n} \sinh \left(k_{2 n} h\right)\right), \\
& S_{n}^{k}=T_{1 n} k_{1 n} \sinh \left(k_{1 n} h\right)\left(P_{n}^{w} T_{2 n}^{h}\right)^{-1}-i n \cos k_{1 n} h\left(P_{n}^{w}\right)^{-1}, \\
& P_{n}^{w}=2 G n^{2}-\rho w^{2}, k_{1 n}^{2}=n^{2}-\alpha^{2} i w j, k_{2 n}^{2}=n^{2}-\beta^{2} i w j(j \downarrow 0),
\end{aligned}
$$

where $A_{\alpha \beta}=\frac{\rho w^{2}}{2 G\left(2 \rho w^{2}-G\left(\alpha^{2}+\beta^{2}\right)\right)}, \quad B_{\alpha \beta}=\frac{\rho^{2} w^{4}}{G\left(\alpha^{2}+\beta^{2}\right)\left(2 \rho w^{2}\right)-G\left(\alpha^{2}+\beta^{2}\right)}$.

All these coefficients are positive, since

$$
2 \rho w^{2}-G\left(\alpha^{2}+\beta^{2}\right)=2 \rho w^{2}-G w^{2}\left(\frac{1}{c_{1}^{2}}+\frac{1}{c_{2}^{2}}\right)=w^{2} G\left(\frac{2}{c_{2}^{2}}-\frac{1}{c_{2}^{2}}-\frac{1}{c_{1}^{2}}\right)=w^{2} G\left(\frac{1}{c_{2}^{2}}-\frac{1}{c_{1}^{2}}\right)>0 \text { by }
$$

virtue of $c_{1}<c_{2}$.

On representing $M_{n}^{h}$ in the form

$$
M_{n}^{h}=\left(M_{n}^{h}+\frac{A_{\alpha \beta}}{|n|}\right)-A_{\alpha \beta} \frac{1}{|n|}
$$

and multiplying (7) by $n$ we get the following discrete Riemann problem

$$
n \Phi_{n+}=-A_{\alpha \beta} \operatorname{sgn}\left(n+\frac{1}{2}\right) \Phi_{n-}+\Gamma_{n}^{\alpha \beta} \Phi_{n-}-n V_{n-},
$$

where

$$
\Gamma_{n}^{\alpha \beta}=n M_{n}^{h}+A_{\alpha \beta} \operatorname{sgn}\left(n+\frac{1}{2}\right) \text { and also }\left|\Gamma_{n}^{\alpha \beta}\right|=0\left(\frac{1}{n^{2}}\right)(n \rightarrow \infty)
$$

The equivalence condition of problems (7) and (8) has the form

$$
\begin{aligned}
& \sum_{n=-\infty}^{\infty}\left(k_{1 n} B_{n}-i n C_{n}\right)=v_{0}, \text { where } C_{n}=-\frac{2 G i n k_{1 n}}{P_{n}^{w}} B_{n}, \\
& B_{n}=\frac{1}{D_{n}^{\alpha \beta}}\left(X_{1 n} T_{2 n}^{h}+X_{2 n} T_{1 n}^{h}\right) ; \quad X_{1 n}=\operatorname{in} \cosh \left(k_{1 n} h\right) \Phi_{n-}, \\
& X_{2 n}=k_{1 n} \sinh \left(k_{1 n} h\right) \Phi_{n-}, \\
& D_{n}^{\alpha \beta}=i n T_{2 n}\left(P_{n}^{w} \sin k_{1 n} h-2 G k_{1 n} k_{2 n} \operatorname{sunh}\left(k_{2 n} h\right)\right)-k_{1} T_{1 n}^{h}\left(P_{n}^{w} \cosh \left(k_{1 n} h\right)-2 G n^{2} k_{2 n} h\right) .
\end{aligned}
$$

On performing the inverse Fourier transform

$$
w^{-1} \Phi_{n \pm}=\sum_{n=-\infty}^{\infty} \Phi_{n \pm} e^{i n x}=\varphi_{ \pm}(x)
$$

and using the formula [2]

$$
w^{-1} \operatorname{sgn}\left(n+\frac{1}{2}\right) \Phi_{n-}=\frac{1}{\pi} \int_{-\pi}^{\pi} \frac{\varphi_{-}(t) e^{i t} d t}{e^{i t}-e^{i x}} .
$$

We reduce the discrete problem (8) to the singular integral equation 


$$
\frac{1}{2 \pi} \int_{-a}^{a} \cot \frac{t-x}{2} \varphi_{-}(t) d t=-2 \sum_{n=1}^{\infty} \Gamma_{n}^{\alpha \beta} \Phi_{n-} \sin n x .
$$

This Hilbert type singular integral equation can be inverted in the class of integrable function functions with the result

$$
\varphi_{-}(x)=\frac{1}{A_{\alpha \beta} X(x)}\left(2 \sum_{n=1}^{\infty} \Gamma_{n}^{\alpha \beta} Q_{n}(x) \Phi_{n^{-}}+a_{0} \cos \frac{x}{2}\right),
$$

where

$$
\begin{aligned}
& X(x)=\sqrt{2(\cos x-\cos a)}, \quad Q_{n}(x)=\sum_{m=0}^{n} \mu_{n-m}(\cos a) \cos \left(m+\frac{1}{2}\right) x, \\
& \mu_{0}(\cos a)=1, \quad \mu_{1}(\cos a)=-\cos a, \quad \mu_{k}(\cos a)=\frac{P_{k-2}(\cos a)-P_{k}(\cos a)}{2 k-1}(k=2,3, \ldots) .
\end{aligned}
$$

The application of the finite Fourier transform to (12) leads to the following infinite system of linear algebraic equations

$$
A_{\alpha \beta} \Phi_{n-}=2 \sum^{\infty} \Gamma_{n}^{\alpha \beta} \Phi_{k-} N_{k n}+a_{0} R_{n}(n=0,1,2, \ldots),
$$

where

$$
\begin{aligned}
& N_{k n}=-\frac{n+1}{2(n-k)}\left(P_{n}(\cos a) P_{k-1}(\cos a) P_{k}(\cos a)\right)(k>1), \\
& R_{n}=\frac{1}{4}\left(P_{n}(\cos a)+P_{n+1}(\cos a)\right), \quad P_{n}(\cos a)=\frac{1}{\pi} \int_{-a}^{a} \frac{\cos \left(n+\frac{1}{2}\right) x d x}{\sqrt{2(\cos x-\cos a)}} \text { are }
\end{aligned}
$$

Legendre polynomials.

Since system (13) can in general be solved approximately, namely using the method of truncation, we set up function spaces and sequence spaces. The solution (12) of equation (11) is in $L_{\rho}(-a, a)$, where $1<\rho<4 / 3$ [8]. Consequently the Fourier coefficient $\Phi_{n-}$ will belong to $l_{\rho}$ where $\rho=p /(p-1)$. Thus we will work in the space $l_{\rho}(p>4)$ with the norm

$$
\Phi_{l_{p}}=\left(\sum_{n=0}^{\infty}\left|\Phi_{n-}\right|^{p}\right)^{1 / p}
$$

where $\Phi=\left\{\Phi_{n-}\right\}_{n=\overline{0, \infty}}$.

The justification of truncating system (13) is a simple consequence of the following theorem whose proof is similar to that given in [9] for the case $p=2$.

Theorem. Suppose that

1. The homogeneous system corresponding to system (13) has only trivial solution in $l_{\rho}$

2. $\sum_{n=0}^{\infty}\left(\sum_{k=1}^{\infty}\left|\Gamma_{n}^{\alpha \beta} N_{k n}\right|^{p /(p-1)}\right)^{p-1}<\infty$;

3. $\sum_{n=0}^{\infty}\left|R_{n}\right|^{p}<\infty$ 
Then the infinite system (13) has a unique solution in $l_{\rho}$. The truncated system will also have a unique solution and the following estimate holds

$$
\Phi-\Phi_{l_{\rho}}^{N} \leq Q_{1}\left(\sum_{n=N+1}^{\infty}\left(\sum_{k=1}^{\infty}\left|\Gamma_{n}^{\alpha \beta} N_{k n}\right|^{p /(p-1)}\right)^{p-1}\right)^{1 / p}+Q_{2}\left(\frac{\sum_{n=N+1}^{\infty}\left|R_{n}\right|^{p}}{\sum_{n=0}^{\infty}\left|R_{n}\right|^{p}}\right)^{1 / p},
$$

where $Q_{1}$ and $Q_{2}$ are constants.

We shall assume that the frequency $w$ differs from those values for which the homogeneous system corresponding to (13) has nontrivial solutions. The fulfillment of the second and the third conditions follows from (14) and (15) together with the estimations

$$
\begin{aligned}
& \left|N_{k n}\right| \sim \frac{C}{\sqrt{n k^{3}}}, \quad R_{n} \sim \frac{C}{\sqrt{n}} \text { for } n \rightarrow \infty \text { and }\left|N_{n n}\right| \leq \frac{\pi}{2}\left(\frac{2}{\pi \sin a}\right)^{1 / 2} \frac{n+1}{\sqrt{n}}, \\
& \left|P_{n}(\cos a)\right| \leq\left(\frac{2}{\pi}\right)^{1 / 2} \frac{1}{\sqrt{\pi} \sin a}(0<a<\pi, n=1,2, \ldots) .
\end{aligned}
$$

Therefore, conditions (2) and (3) are satisfied as $p>4$.

Recall that $\Gamma_{n}^{\alpha \beta} \sim 0\left(k^{-2}\right)$. Additionally we have

$$
\left\|\Phi-\Phi^{N}\right\|_{l_{p}} \leq \frac{C}{(N+1)^{(p-2) / 2 p}}
$$

Thus the approximate solution of the singular integral equation (11) is given by the formula

$$
\tilde{\varphi}_{-}(x)=\frac{1}{A_{\alpha \beta} X(x)}\left(2 \sum_{n=1}^{N} \Gamma_{n}^{\alpha \beta} Q_{n}(x) \Phi_{n-}+a_{0} \cos \frac{x}{2}\right) .
$$

Using formula (12) and taking into account boundary condition (2) we get the expression for the contact stress

$$
p(x, t)=-\sigma_{y}(x, 0, t)=-\frac{e^{-i \omega t}}{A_{\alpha \beta} X(x)}\left(2 \sum_{n=1}^{\infty} \Gamma_{n}^{\alpha \beta} \Phi_{n-} Q_{n}(x)+a_{0} \cos \frac{x}{2}\right) .
$$

The quantity $a_{0}$ included in (12) is still to be defined. In fact the equation of motion of the punch is [10].

$$
M \frac{d^{2} v}{d t^{2}}=e^{-i \omega t}\left(P_{0}-P_{R}\right)
$$

where $M$ is the mass of the punch; $P_{0}$ is the amplitude of the force acting on the punch, and $P_{R}$ is the reaction of the elastic rectangle.

$$
P_{R}=-\int_{-a}^{a} \sigma_{y}^{*}(x, 0) d x=\int_{-a}^{a} \varphi_{-}(x) d x=-\frac{\pi}{A_{\alpha \beta}} a_{0} .
$$

Substituting this expression together with $v=v_{0} e^{-i \omega t}$ into (21) we get

$$
-M w^{2} v_{0}=P_{0}+\frac{2 G a_{0} \pi}{A_{\alpha \beta}}
$$




\section{DISCUSSION OF THE RESULTS OF THE STUDY}

Thus the amplitude $v_{0}$ and the quantity $a_{0}$ can be calculated from equations (9) and (23). The real values for which $v^{*}(x, 0) \rightarrow \infty$, the resonance frequencies, are the real roots of the resonance equations

$$
D_{n}^{\alpha \beta}=0,2 G n^{2}-\rho w^{2}=0(n=1,2, \ldots, N) .
$$

Let $\bar{w}=w a_{T} / c_{2}^{2}, \tau=t c_{2}^{3} / a_{T}, \bar{x}=x / a$ are the dimensionless frequency, time and coordinate. $\bar{M}=M / \rho a_{T}^{2}$ is the dimensionless mass.

Suppose that $\bar{w}=0.1, \bar{M}=1, v=0.3, N=10$. In the table the values of the contact stress corresponding to different values of $\bar{x}$ are exhibited, when $\tau=2 \pi$.

Table 1

\begin{tabular}{|c|c|c|c|c|c|c|}
\hline $\bar{x}$ & 0 & 0,1 & 0,2 & 0,3 & 0,4 & 0,5 \\
\hline$\frac{\tilde{p}(\bar{x}, \tau)}{P_{0}}$ & 0,4294 & 0,4302 & 0,4324 & 0,4422 & 0,4682 & 0,4889 \\
\hline $\bar{x}$ & 0,6 & 0,7 & 0,8 & 0,9 & 0,95 & 0,99 \\
\hline$\frac{\tilde{p}(\bar{x}, \tau)}{P_{0}}$ & 0,5174 & 0,5713 & 0,6515 & 0,8653 & 1,1388 & 2,3455 \\
\hline
\end{tabular}

The unknown amplitude of the vibration of the punch is $v_{0}=0,1217 P_{0}$. If $p=5$ then the estimation of the error is subjected to the inequality

$$
\left\|\Phi-\Phi^{N}\right\|_{l_{5}} \leq \frac{C}{3,278}
$$

Note that the values of the contact stresses increase unboundedly at the vicinities of the end point of the contact interval.

\section{CONCLUSIONS}

On choosing the number $\mathrm{N}$ and using the corresponding formulas we can get the approximate solution of the contact problem for the rectangle to find the contact stress up to any prescribed accuracy.

\section{References}

1. Cherskii, Y. I. (1961). Svedenie periodicheckikh zadach matematicheskoi fiziki k singulyarnym integralnym uravneniyam s yadrom Koshi. Dokl. Akad. Nauk SSSR, 140, 69-72.

2. Gakhov, F. D., Cherskii, Y. I (1978). Uravneniya tipa svertki. M.: Nauka, 295.

3. El-Sheikh, M. G. (1992). The integral equation formation of mixed finite time dependent elastic problems. Computers Math. Applic., vol. 24, 4, 3-14.

4. El-Sheikh, M. G., Khalipa, M. E., Gavdzinski, V. N. (1998). The methods of integral equation formulation and the unbounded solutions of elastic contact problems. Computers Math. Applic., Vol. 36, 1, 33-39.

5. Gavdzinski, V. N., El-Sheikh, M. G., Maltseva, E. V. (2002). On the justification of approximate unbounded solutions of mixed plane boundary value problems. Math. and Comp. in Similation, 59, $533-539$. 
6. Gavdzinski, V. N., El-Sheikh, M. G., Maltseva, E. V. (2012). The thermoelastic contact problem for a cylinder. Visnyk ODABA, 45, 44-51.

7. Novatski, V. (1975). Teoriya uprugosti. M.: Mir, 872.

8. Titchmarsh, E. C. (1980). Teoriya funktsyi. M.: Nauka, 463.

9. Kantarovich, L. V., Akilov, G. P. (1971). Funktsionalnyi analiz. M.: Nauka, 742.

10.Seimov, V. M. (1976). Dinamicheskie kontaktnye zadachi. K.: Naukova dumka, 283.

\section{Литература}

1. Черский Ю. И. Сведение периодических задач математической физики к сингулярным интергальным уравнениям с ядром Коши / Ю. И. Черский // Доклад Академика Наук СССР. - 1961. - №140. - С. 69-72.

2. Гахов Ф. Д. Уравнения типа свертки / Ф. Д. Гахов, Ю. И. Черский. - М.: Наука, 1978. - 295 с.

3. El-Sheikh M. G. The integral equation formation of mixed finite time dependent elastic problems / El-Sheikh. // Computers Math. Applic.. - 1992. - №24. - C. 3-14.

4. El-Sheikh M. G. The methods of integral equation formulation and the unbounded solutions of elastic contact problems / M. G. El-Sheikh, M. E. Khalipa, V. M. Gavdzinski. // Computers Math. Applic.. - 1998. - №36. - C. 33-39.

5. Gavdzinski V. N. On the justification of approximate unbounded solutions of mixed plane boundary value problems / V. N. Gavdzinski, M. G. El-Sheikh, E. V. Maltseva. // Math. and Comp. in Similation. - 2002. - №59. - C. 553-539.

6. Gavdzinski V. N. The thermoelastic contact problem for a cylinder / V. N. Gavdzinski, M. G. ElSheikh, E. V. Maltseva. // Visnyk ODABA. - 2012. - №45. - C. 44-51.

7. Новатский В. Теория упругости / В. Новатский. - М.: Мир, 1975. - 872 с.

8. Титчмарш Е. Теория функций / Е. Титчмарш. - М.: Наука, 1980. -463 с.

9. Кантарович Л. В. Функциональный анализ / Л. В. Кантарович, Г. П. Акилов. - М.: Наука, 1971. $-742 \mathrm{c}$.

10.Сеймов В. М. Динамические контактные задачи / В. М. Сеймов. - К.: Наукова думка, 1976. $283 \mathrm{c}$.

\section{Gavdzinski Vladislav}

Odessa State Academy of Civil Engineering and Architecture, Ph.D., professor

Didrihsona str.,4 Odessa, Ukraine 65029

gavdzinskivn@gmail.com,

ORCID: 0000-0002-3152-4662

El-Sheikh M.G.

Ain Shams University, Cairo, Egypt, Ph.D., professor

Nour Mosque, 38 Abbasia Next, El-Mohamady, Al Waili, Cairo,Egypt

medasu@gmail.com

ORCID: 0000-0001-6867-4878

Maltseva Evgenia

Odessa National Economic University

Preobrazhenskaya str.,8 Odessa, Ukraine 65082

mmmd@oneu.edu.ua

ORCID: 0000-0002-8769-023X

\section{Для посилань:}

Гавдзинський В. Н. Застосування сингуляторних інтегральних рівнянь при рішенні деяких контактних завдань теорії пружності / В. Н. Гавдзинський, М. Г. Ель-Шейх, С. В. Мальцева // Механіка та математичні методи. - 2019. - №1. - С. 46-55.

For references:

Gavdzinski, V., El-Sheikh, M. G., Maltseva, E. (2019). Application of singular integral equations in solving some contact problems in theory of elasticity. Mechanics and Mathematical Methods, 1, 46-55. 